\title{
"The viability of asset price channel implementation to the monetary transmission mechanism of Ukraine"
}

\author{
AUTHORS \\ Serhiy Kozmenko (D https://orcid.org/0000-0001-7710-4842 \\ Oleksiy Plastun (D https://orcid.org/0000-0001-8208-7135
}

Serhiy Kozmenko and Oleksiy Plastun (2016). The viability of asset price

ARTICLE INFO channel implementation to the monetary transmission mechanism of Ukraine. Investment Management and Financial Innovations, 13(4), 58-67. doi:10.21511/imfi.13(4).2016.05

DOI http://dx.doi.org/10.21511/imfi.13(4).2016.05

RELEASED ON Thursday, 15 December 2016

JOURNAL "Investment Management and Financial Innovations"

FOUNDER LLC "Consulting Publishing Company "Business Perspectives"

NUMBER OF REFERENCES

0

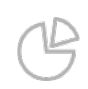

NUMBER OF FIGURES

0

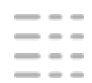

NUMBER OF TABLES

0

(c) The author(s) 2022. This publication is an open access article. 
Serhiy Kozmenko (Ukraine), Oleksiy Plastun (Ukraine)

\title{
The viability of asset price channel implementation to the monetary transmission mechanism of Ukraine
}

\begin{abstract}
Monetary transmission mechanism is a key element of the central bank's activity, where the asset price channel plays an important role among others. Although in Ukraine it is not used. The viability analysis of this channel implementation in the monetary transmission mechanism of Ukraine is executed and the finding about current unavailability for this is made. However, the perspectivity and necessity of asset price channel implementation in the monetary transmission of Ukraine already today requires the creation of theoretic base appropriate for this. Therefore some propositions on the assets price channel implementation in the monetary transmission mechanism of Ukraine are offered.
\end{abstract}

Keywords: Central Bank, the asset price channel, monetary transmission mechanism, monetary policy, Tobin's q effect.

JEL Classification: E52, E58.

\section{Introduction}

Monetary transmission mechanism is an important element of the Central Bank's activity of the country. It consists of transmission channels. F. Mishkin (1995) outlines four monetary transmission channels: the interest rate channel, the currency rate channel, the asset price channel, the credit channel (Mishkin, 1995).

As modern economic system is characterized by rather dynamic development and frequent revolutionary changes, especially in the sphere of finance, the transmission mechanism has to evolve constantly. For instance, the spreading of behavioral finance in modern economic theory has led to the appearance of economic subjects' expectation channels. Also rather often the subchannels are outlined as parts of transmission channels (separate ways of monetary impulse spreading), connected with currency complication, financial markets development, new financial instruments appearance.

Notwithstanding, in a whole typical monetary transmission channel list, they may be different in different countries, that is, determined by the specific of economic system, organization and structure of financial market, state regulation system and so on. For instance, in Italy and Belgium, the portfolio channel is outlined, and in France - inflation channel and so on.

There is no universal mechanism of monetary transmission. Each country develops its own one, with a unique transmission list of channels and

\footnotetext{
${ }^{(c)}$ Serhiy Kozmenko, Oleksiy Plastun, 2016.

Serhiy Kozmenko, Doctor of Economics, Professor of Department of Banking, Kharkiv National University of Economics, Ukraine.

Oleksiy Plastun, Doctor of Economics, Professor of Department of International Economics, Sumy State University, Ukraine.
}

subchannels, that depend on the nuances of both monetary policy of Central Bank, and on the peculiarities of economic system of definite country. For instance, transmission monetary mechanism in Russia consists of three basic channels: the exchange rate channel, the interest rate channel, credit channel and derived from the basic one - assets evaluation channel, as at the same time in Kazachstan monetary transmission mechanism includes credit, costs and currency channels (Ivanchenko, 2010).

In Ukraine monetary transmission mechanism is still on the development stage (see the works of Kozmenko and Savchenko, 2011, 2012) (Kozmenko, Savchenko, 2013, p.10). Its main difference from the analogues of developed countries is full absence of assets price channel. In this paper we have tried to find whether it is the drawback of the National Bank of Ukraine or objectively this monetary transmission channel is inappropriate for today.

Though evolutionary development reveals implementation of this element into the monetary transmission mechanism is inevitable, therefore in the paper we have proposed recommendations concerning incorporation of assets price channel in transmission mechanism of monetary policy of Ukraine.

\section{Monetary transmission mechanism in Ukraine}

The role and place issue of assets price channel in transmission mechanism is not completely solved in the academic circles.

One of the first to raise it was Poole (1970), who proved that the Central Bank of the country has to stand against the price dynamics of financial markets with the aim of alleviation of their impact 
on the real sector of economy. Price channels impact researches on monetary policy were made by Bernanke, Mishkin, Gertler, Cecchetti, Roger et al. The part of them drove to the conclusion the Central Bank should not be responsible for the assets prices changes (Bernanke, Mishkin, 1997, Bernanke, Gertler, 2001).The opposite findings were received by Cecchetti et al. (2000), who proved substantially on theoretical and empirical levels the viability of price considering on financial assets while monetary policy is realized (Cacchetti et al., 2000. For these purposes, the model created by Batini and Nelson (2000) was used.

An important finding was formed in the research of Ivanov and Lavrinovich (2008), which means proving the fact the role of assets price channel in transmission mechanism raises in time, which is caused by the raise of international capital mobility. Research on monetary impulses of research impact on market prices of stock assets in Russia was held by Ivanchenko (2010), who proved the existence of statistically significant relation between the dynamics and change of key parameters of monetary policy and stock market behavior in Russia. He also proved that the Russian stock market directly (without participation of bank system as a medium) impacts the gross investments in the country and GDP level.

Not taking into account the absence of unity in academic circles, the experience tells asset price channel is an important part of transmission mechanism.

In terms of Ukraine, the modern mechanism of monetary transmission consists of 4 channels (see Kozmenko et al., 2014 for details): the interest rate channel, currency course (as a part of asset prices); credit channel, economic subjects' expectations channel.

The analysis of current practice of NBU and quarterly predicting model (QPM), used as a base for making decisions of National Bank of Ukraine, prove that the assets price channel in Ukraine is used very restrictively, rather from the point of exchange rate. Price dynamics and other financial assets (shares, stock, real estate holdings, etc.) are practically ignored while making decisions. That is, in fact, only the channel of currency course is present.

To our mind, such an approach is feasible in terms of undeverloped financial market, but the growing role of financial markets, transactions volumes on them and financial assets, that are traded on them, will lead to the review of current approach and taking into account the prices on financial assets while making decisions of monetary policy. In the work of Kozmenko and Plastun (2012), we gave the list of factors, causing the information importance in assets prices while making decisions in modern economy.

We will try to prove the price analysis importance on financial assets in the implementation of monetary policy of Ukraine. Asset prices impact the actions of Central Banks of the USA, EU countries and many others. Due to the findings of research held by Roger and Sterne (1999), the majority of 77 respondents of Central Banks approved that the price volatility on assets impacted their monetary policy. While implementing monetary policy, Central Bank has to calculate its possible impact on the country's economy. The example of price bubble of Japan in 1980s witnesses the Central Bank itself may sometimes become the generator of system crisis in economy. Central Bank's policy, directed on the enlarging of monetary base and liquidity saturation of economy, may lead to the appearance of price (they are also called stock, financial, speculative, market) bubbles. Their collapse, in turn, is accompanied by significant losses of economic entities and even may lead to the appearance of system economic crisis.

Though, financial assets prices generate the signals of price bubbles formation, thus, providing the possibility for Central Bank to make needed corrections in its monetary policy. The case study for such interaction is current US monetary policy, when in response to sharp raise of US stock market with the aim to prevent crisis there the fed at the end of 2015, started the cycle of interest rates heightening. A thorough research dedicated to the Central Bank's role in formation and collapse of price bubbles was held by Kent and Lowe (1997).

Thus, incorporation of information according to the prices on financial markets is an important element of monetary policy of Central Bank. In regards of experience of developed countries, we may confirm that the price assets channel implementation into monetary policy transmission mechanism in Ukraine is inevitable. Monetary policy evolutionary transmission mechanism of Ukraine will be close to Western analogues, such as the Central Bank of England holds (Fig. 1). 


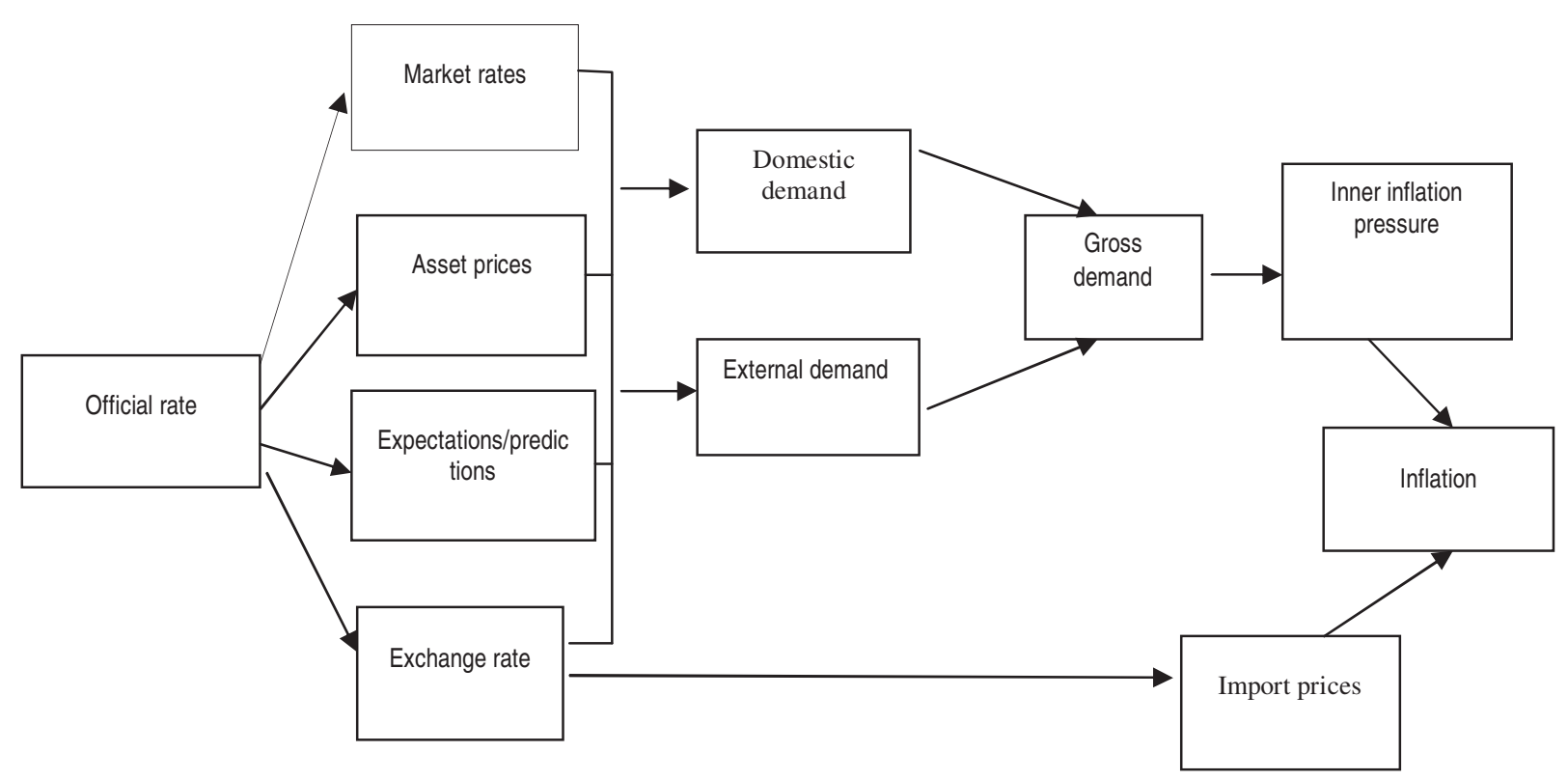

Fig. 1. Monetary policy transmission mechanism of the bank of England

Under such structure of transmission mechanism, it is predicted the thatchanges in instruments parameters of monetary policy will lead to the changes in market value of key types of financial assets: shares, stock, real estate holdings which, in it turn, will influence the economy of the country.

Thus, the Central Bank has significant instruments to regulate prices on financial markets. It may enlarge or, on the contrary, lessen relative investment attractiveness of stock, shares, real estate holdings. This, in it turn, influences investment activity in the country in whole and in separate economic sectors.

Thus, asset price channel is an important part of monetary policy transmission mechanism, which determines the impact of monetary policy on real economy sector because of change of relative prices of capital and real assets.

To prove the viability/unviability of asset price channel implementation into monetary transmission mechanism of Ukraine, there should be held its empirical evaluation.

\section{Research methodology}

In this research, we will make an attempt to prove the viability of proper asset price channel implementation into the NBU's monetary transmission mechanism.

We should admit that because of the lack of appropriate statistical data, the examination will be made not through the evaluation of Tobin's classical channels (with the use of renewed cost of capital parameters), but by the analysis of monetary impulses transition on the prices of separate assets: shares, real estate.The existence of asset price channel was examined on the example of stock market and real estate market of Ukraine.

To evaluate the existence of asset price channel, we used the correlation analysis with and without usage of lag variables. The need to use lags is connected with potential delays in the impulses transition from bank system to financial market of Ukraine.

As impulse generating variables we took under consideration the parameters by key instruments of $\mathrm{NBU}$, as well as intrabanking credit market parameters that are actually derivatives from monetary policy basic instruments.

The list of parameters for impulse characterization of NBU and banking system, which were under consideration in this work, includes discount rate of NBU (\%); weighted average rate on all NBU instruments (\%); credit rate granted by tender (\%); overnight credit rate $(\%)$; repo transactions rate $(\%)$; monetary base volume ( $\mathrm{mln}$. hrn.); whole volume of NBU given credit resources (mln. hrn.); weighted average credit rate provided by NBU (\%).

The list of parameters for Ukrainian stock market characterization, includes: PFTS Index; UX Index.

To characterize the Ukrainian real estate market, we used average price parameters for the secondary real estate in Kyiv. This choice was due to, one the one hand limited statistic data and access to them and, on the other hand real estate market in Kyiv is the most dynamic and the one that reacts actively to these or that changes in the outer surrounding.

For the analysis, we used two types of data: monthly and daily. The first type is the mostly spread representation of statistic data for economic 
parameters, that is why it was taken as a basis. In terms of the second one (daily data), they were used with the aim of taking into account information absorption speed of stock markets. It is meant that the new information, including the change of NBU instrument parameters, may be relatively fast incorporated in the price of capital issues, as a result, the reactions cannot be vivid on monthly data.

In terms of the analysis period, in the work, two periods were used: $2005-2015,2008-2015$. The first period is the highest possible from the point of statistic data existence from NBU in monthly and daily measures. The need to use the second data period is due to UX index data began to be published in 2008.

\section{Empirical results}

3.1. Ukrainian stock market analysis. For the general analysis of Ukrainian stock market reactions to the changes of different NBU instrument parameters, correlation matrix was formed on the basis of monthly data (Table 1).

Table 1. Correlation matrix characterizing the Ukrainian stock market reactions to the changes of monetary policy instruments (monthly data)

\begin{tabular}{|l|c|c|c|c|c|c|c|}
\hline & $\begin{array}{c}\text { Discountrate } \\
\text { of } \\
\text { NBU }\end{array}$ & $\begin{array}{c}\text { Weighted } \\
\text { average rate on } \\
\text { all NBU } \\
\text { instruments }\end{array}$ & $\begin{array}{c}\text { Credit rate } \\
\text { granted by tender }\end{array}$ & $\begin{array}{c}\text { Overnightcreditrat } \\
\text { e }\end{array}$ & $\begin{array}{c}\text { Repotransactionsrat } \\
\text { e }\end{array}$ & $\begin{array}{c}\text { PFTS } \\
\text { index * }\end{array}$ & $\begin{array}{c}\text { UX index } \\
* *\end{array}$ \\
\hline DiscountrateofNBU & 1 & 0.92 & 0.90 & 0.94 & 0.86 & 0.02 & -0.05 \\
\hline $\begin{array}{l}\text { Weighted average rate on } \\
\text { all NBU instruments }\end{array}$ & 0.92 & 1 & 0.95 & 0.90 & 0.93 & 0.10 & 0.02 \\
\hline $\begin{array}{l}\text { Credit rate granted by } \\
\text { tender }\end{array}$ & 0.90 & 0.95 & 1 & 0.93 & 0.95 & 0.08 & 0.01 \\
\hline Overnightcreditrate & 0.94 & 0.90 & 0.93 & 1 & 0.91 & 0.00 & -0.07 \\
\hline Repotransactionsrate & 0.86 & 0.93 & 0.95 & 0.91 & 1 & -0.02 & -0.09 \\
\hline PFTS index & 0.02 & 0.10 & 0.08 & 0.00 & -0.02 & 1 & 0.995 \\
\hline UX index & -0.05 & 0.02 & 0.01 & -0.07 & -0.09 & 0.995 & 1 \\
\hline
\end{tabular}

Notes:2005-2015 data, 2008-2015 data.

As the table data show, basic parameters of NBU instruments are closely connected with one another, though absolutely uncorrelated with basic indexes of Ukrainian stock market. It means either lack of connection between Ukrainian stock market dynamics and changes in NBU instrument parameters (practically it means the lack of monetary policy influence on the Ukrainian stock market) or the existence of delay in impulse transition from NBU to stock market.

To confirm the hypothesis on the presence of lags in impulse transition from NBU to the Ukrainian stock market, the correlation coefficients were calculated for different time lags variants (Table 2).

Table 2. Lag analysis of the Ukrainian stock market reactions to the changes of MP instruments (monthly data)

\begin{tabular}{|c|c|c|c|c|c|c|}
\hline \multirow{2}{*}{$\begin{array}{l}\text { Lag size in } \\
\text { months }\end{array}$} & \multicolumn{2}{|c|}{ DiscountrateofNBU } & \multicolumn{2}{|c|}{ Weighted average rate on all NBU instruments } & \multicolumn{2}{|c|}{ Repotransactionsrate } \\
\hline & PFTS index * & UX index ** & PFTS index * & UX index ** & PFTS index * & UX index ** \\
\hline 0 & -0.06 & -0.05 & 0.03 & 0.02 & -0.05 & -0.09 \\
\hline 1 & -0.10 & -0.08 & 0.00 & 0.01 & -0.06 & -0.08 \\
\hline 2 & -0.13 & -0.11 & -0.04 & 0.00 & -0.06 & -0.05 \\
\hline 3 & -0.16 & -0.13 & -0.07 & 0.00 & -0.06 & -0.02 \\
\hline 4 & -0.17 & -0.14 & -0.10 & -0.01 & -0.07 & -0.01 \\
\hline 5 & -0.18 & -0.13 & -0.11 & 0.00 & -0.07 & 0.00 \\
\hline 6 & -0.16 & -0.09 & -0.12 & 0.01 & -0.07 & 0.03 \\
\hline 7 & -0.11 & -0.03 & -0.13 & 0.02 & -0.05 & 0.07 \\
\hline 8 & -0.05 & 0.04 & -0.11 & 0.06 & -0.02 & 0.13 \\
\hline 9 & 0.02 & 0.13 & -0.08 & 0.11 & 0.04 & 0.22 \\
\hline 10 & 0.11 & 0.22 & -0.03 & 0.17 & 0.09 & 0.29 \\
\hline 11 & 0.19 & 0.32 & 0.04 & 0.25 & 0.15 & 0.36 \\
\hline 12 & 0.26 & 0.40 & 0.11 & 0.32 & 0.20 & 0.44 \\
\hline 13 & 0.33 & 0.47 & 0.18 & 0.39 & 0.25 & 0.50 \\
\hline 14 & 0.39 & 0.54 & 0.24 & 0.46 & 0.29 & 0.55 \\
\hline 15 & 0.43 & 0.59 & 0.31 & 0.53 & 0.31 & 0.57 \\
\hline 16 & 0.47 & 0.63 & 0.37 & 0.58 & 0.35 & 0.60 \\
\hline 17 & 0.51 & 0.67 & 0.44 & 0.64 & 0.41 & 0.66 \\
\hline 18 & 0.55 & 0.71 & 0.49 & 0.68 & 0.46 & 0.71 \\
\hline
\end{tabular}


Table 2. Lag analysis of the Ukrainian stock market reactions to the changes of MP instruments (monthly data)

\begin{tabular}{|l|l|l|l|l|l|l|}
\hline 19 & 0.60 & 0.76 & 0.55 & 0.74 & 0.52 & 0.77 \\
\hline 20 & 0.64 & 0.81 & 0.61 & 0.80 & 0.57 & 0.82 \\
\hline 21 & 0.69 & 0.86 & 0.67 & 0.84 & 0.62 & 0.87 \\
\hline 22 & 0.73 & 0.89 & 0.71 & 0.86 & 0.66 & 0.89 \\
\hline 23 & 0.75 & 0.91 & 0.73 & 0.86 & 0.67 & 0.88 \\
\hline 24 & 0.77 & 0.89 & 0.75 & 0.86 & 0.68 & 0.84 \\
\hline
\end{tabular}

There appears very close connection when the lag size is 21-24 months. At the same time UX index demonstrates much better results that indirectly confirms the fact, that for today, the Ukrainian exchange is the best indicator of exchange market of Ukraine. It is connected with the fact that the most liquid trade with shares takes place on the Ukrainian stock.

Thus, the previous hypothesis about the existence of lag in reactions of stock market to the changes of monetary policy is confirmed. Nevertheless, it needs additional confirmation, for which we make the analysis of Ukrainian stock market reactions to the changes of capital base (Table 3).

Table 3. The analysis of Ukrainian stock market reactions to the changes of capital base (monthly data)

\begin{tabular}{|c|c|c|}
\hline Lag size in months & PFTS & UX \\
\hline 0 & 0.36 & -0.29 \\
\hline 1 & 0.35 & -0.26 \\
\hline 2 & 0.33 & -0.21 \\
\hline 3 & 0.32 & -0.17 \\
\hline 4 & 0.31 & -0.13 \\
\hline 5 & 0.29 & -0.08 \\
\hline 6 & 0.28 & -0.04 \\
\hline 7 & 0.26 & -0.02 \\
\hline 8 & 0.24 & -0.01 \\
\hline 9 & 0.23 & -0.03 \\
\hline 10 & 0.20 & -0.09 \\
\hline 11 & 0.18 & -0.14 \\
\hline 12 & 0.16 & -0.19 \\
\hline 13 & 0.14 & -0.25 \\
\hline 14 & 0.12 & -0.34 \\
\hline 15 & 0.11 & -0.41 \\
\hline 16 & 0.09 & -0.47 \\
\hline 17 & 0.08 & -0.51 \\
\hline 18 & 0.07 & -0.55 \\
\hline 19 & 0.05 & -0.58 \\
\hline 20 & 0.03 & -0.63 \\
\hline 21 & 0.01 & -0.67 \\
\hline 22 & -0.01 & -0.71 \\
\hline 23 & -0.03 & -0.74 \\
\hline 24 & -0.04 & -0.77 \\
\hline 25 & -0.06 & -0.79 \\
\hline 26 & -0.07 & -0.79 \\
\hline 27 & -0.09 & -0.77 \\
\hline
\end{tabular}

Notes: 2005-2015 data, 2008-2015 data

The received results witness the benefits of hypothesis on the existence of lag in reactions of stock market to the impulses of NBU side. With the absence of lag correlation, relation between capital base dynamics and changes in leading stock indexes of Ukraine is absent. Although on the condition of lag use for 20 and more months there appears a strong negative relation between capital base dynamics and Ukrainian stock market.

To consider the possible too fast reaction of stock market to the changes of monetary policy parameters, NBU and intrabank market instruments, there should be held the analysis with the use of shorter time intervals. It is referred to daily data.

For daily analysis we use the NBU data according to general volume of provided by National bank of Ukraine credit resources to bank institutions of Ukraine, as well as parameters of this crediting as weighted average rate, as well as overnight transactions rate.

The results of correlation analysis with the leading indexes of Ukrainian stock exchanges are shown in Table 4.

Table 4. The general analysis of Ukrainian stock market reactions to the changes of NBU credit parameters (daily data)

\begin{tabular}{|l|c|c|c|c|c|}
\hline \multicolumn{1}{|c|}{ Parameters } & $\begin{array}{c}\text { The general } \\
\text { volume of } \\
\text { provided credit } \\
\text { resources, } \\
\text { mln. hrn. }\end{array}$ & $\begin{array}{c}\text { Weighted } \\
\text { averager } \\
\text { ate, \% }\end{array}$ & $\begin{array}{c}\text { Including } \\
\text { overnight } \\
\text { transact- } \\
\text { tions }\end{array}$ & $\begin{array}{c}\text { PFTS } \\
\text { Index }\end{array}$ & $\begin{array}{c}\text { UX } \\
\text { Index }\end{array}$ \\
\hline $\begin{array}{l}\text { The general } \\
\text { volume of } \\
\text { provided credit } \\
\text { resources, mIn. } \\
\text { hrn. }\end{array}$ & 1 & 0.27 & 0.29 & -0.09 & -0.08 \\
\hline $\begin{array}{l}\text { Weightedavera } \\
\text { gerate, \% }\end{array}$ & 0.27 & 1 & 0.99 & -0.32 & -0.35 \\
\hline $\begin{array}{l}\text { Among others } \\
\text { overnight } \\
\text { transactions }\end{array}$ & 0.29 & 0.99 & 1 & -0.32 & -0.34 \\
\hline PFTS index & -0.09 & -0.32 & -0.32 & 1 & 0.99 \\
\hline UX index & -0.08 & -0.35 & -0.34 & 0.99 & 1 \\
\hline
\end{tabular}

Notes: 2008-2015 data

As the analysis of Ukrainian stock market reactions witnesses the changes of crediting parameters of NBU on the basis of daily data without lags use, correlation relation is absent. Nevertheless, as the reaction might happen in the middle of the month (for example, with the lag of 5 or 10 days), to decline the hypothesis on the presence of too fast 
reaction is too early. To check it, as well as for more detailed analysis with the lags use, we made the analysis of Ukrainian stock market reactions to the changes of crediting parameters of NBU (daily data) with the use of lags for PFTS index (Table 5) and UX index (Table 6).

Table 5. Analysis of Ukrainian stock market reactions to the changes of crediting parameters of NBU (daily data) with the use of lags for PFTS index

\begin{tabular}{|c|c|c|c|}
\hline $\begin{array}{c}\text { Lag size in } \\
\text { days }\end{array}$ & $\begin{array}{c}\text { The general volume } \\
\text { of provided credit } \\
\text { resources, mln. hrn. }\end{array}$ & $\begin{array}{c}\text { Weightedaverage } \\
\text { rate, \% }\end{array}$ & $\begin{array}{c}\text { Including } \\
\text { overnight } \\
\text { transactions }\end{array}$ \\
\hline 0 & 0.05 & -0.25 & -0.26 \\
\hline 5 & 0.02 & -0.26 & -0.27 \\
\hline 10 & 0.00 & -0.27 & -0.28 \\
\hline 20 & -0.04 & -0.28 & -0.29 \\
\hline 30 & -0.07 & -0.29 & -0.30 \\
\hline 60 & -0.18 & -0.29 & -0.30 \\
\hline 120 & -0.37 & -0.33 & -0.34 \\
\hline 180 & -0.46 & -0.29 & -0.30 \\
\hline 360 & -0.32 & 0.04 & 0.04 \\
\hline 720 & 0.13 & 0.08 & 0.11 \\
\hline
\end{tabular}

Notes: 2005-2015 data.

As the data of Table 5 witness, the PFTS index dynamics does not influence the changes in crediting parameters. Such results may be explained, on the one hand, by lesser representativeness of PFTS index, that is less representative comparing to UX index, and on the other hand the daily fluctuations of stock market have more predispositions to accidental changes character (these explanations are given in the framework hypothesis of effective market).

To confirm/decline the first supposition concerning less representativeness of PFTS index, the analysis of Ukrainian stock market reactions to the changes of crediting parameters of NBU (daily data) with the use of lags for UX index was held (Table 6).

Table 6. Analysis of Ukrainian stock market reactions to the changes of crediting parameters of NBU (daily data) with the use of lags for UX index

\begin{tabular}{|c|c|c|c|}
\hline $\begin{array}{c}\text { Lag size } \\
\text { in days }\end{array}$ & $\begin{array}{c}\text { The general volume } \\
\text { of provided credit } \\
\text { resources, mln. hrn. }\end{array}$ & $\begin{array}{c}\text { Weightedaverage } \\
\text { rate, \% }\end{array}$ & $\begin{array}{c}\text { Including } \\
\text { overnight } \\
\text { transactions }\end{array}$ \\
\hline 0 & -0.08 & -0.35 & -0.34 \\
\hline 5 & -0.11 & -0.35 & -0.35 \\
\hline 10 & -0.13 & -0.36 & -0.36 \\
\hline 20 & -0.18 & -0.36 & -0.37 \\
\hline 30 & -0.22 & -0.36 & -0.37 \\
\hline 60 & -0.33 & -0.34 & -0.35 \\
\hline 120 & -0.55 & -0.34 & -0.35 \\
\hline 180 & -0.65 & -0.28 & -0.29 \\
\hline 360 & -0.52 & 0.08 & 0.07 \\
\hline 720 & 0.68 & 0.31 & 0.34 \\
\hline
\end{tabular}

Notes: 2008-2015 data.
Adding lags does not change the whole picture radically: strong relation between basic parameters that characterize NBU crediting and UX index dynamics is not found.

The findings in general contradict those for monthly data. The explanation for this may be the accidental character of daily price fluctuations on Ukrainian stock market.

Thus, to analyze the relation to use daily data is inappropriate.

The underdevelopment of Ukrainian stock market, low sales and liquidity level on it, small quantity of sellers give the condition for lack of tight and operative connection between the actions of NBU and price movement on stock market. It is also an argument for the lack of time of asset price channel in monetary policy transmission mechanism.

The problem of Ukrainian stock market lies in almost its total disconnect from economic realities. Correlation level relation between PFTS index and nominal GDP dynamics is -0.53 . Thus, the relation is too weak, but which is more symptomatic, the character of this relation is feedback. That is country economy and stock market development trajectories are different. It is even possible to make a conclusion about the autonomy of stock market of Ukraine and its functioning in its own reality. In favor of the fact the stock market does not have direct impact on GDP, witnesses the relation level value between capital investment level and stock market dynamics. Correlation coefficient meaning 0.22 shows the benefits of its absence.

Though evolutionary development of economic system will lead to capital movement through Ukrainian stock market activization processes, to the growing of its volumes and significance in economy. All this is due to the need and viability of its implementation into transmission mechanism as adding additional channel - asset price channel.

Thus, to analyze the transition mechanism of impulses from NBU to the stock market, the use of monthly data is appropriate, as daily data have mainly the features of accident values, and that's why cannot be used as purpose functions from this or that parameters of monetary policy; while the development of transmission mechanism model for price channel, at least on the research date, the use of time lags transition impulses from MP to price channel in the period of two years are appropriate, instrument parameters of NBU that have lag influence on the dynamics of Ukrainian stock market, is the NBU discount rate, weighted average rate on all NBU instruments, repo transactions rate, capital base volume. 
3.2. Real estate market analysis of Ukraine. The results of lag free correlation analysis of Ukrainian real estate market to the changes of MP instruments are presented in Table 7 . Instant reactions to the changes of MP parameters on the Ukrainian real estate market were not evidenced. That is if this channel acts, then with some delay.

Table 7. Correlation matrix characterizing Ukrainian real estate market reaction to the changes of MP instruments (monthly data) for 2006-2015*

\begin{tabular}{|l|l|}
\hline \multicolumn{1}{|c|}{ Parameter } & \multicolumn{1}{|c|}{$\begin{array}{c}\text { Correlation } \\
\text { coefficient }\end{array}$} \\
\hline DiscountrateofNBU & 0.31 \\
\hline Weighted average rate on all NBU instruments & 0.22 \\
\hline Overnight credit rate & 0.14 \\
\hline
\end{tabular}

\begin{tabular}{|l|l|}
\hline Repo transactions rate & 0.07 \\
\hline Credit rate granted by tender & 0.09 \\
\hline Capital base & -0.52 \\
\hline PFTS index & 0.31 \\
\hline
\end{tabular}

Notes: as the analysis object, the prices on the secondary real estate market in Kyiv are presented

To prove the latest supposition and lag parameters determining Ukrainian real estate market reactions, analysis was held to the changes of MP instruments (Table 8).

The tightest relation is vivid between real estate prices and changes in instrument parameters with time lag of 12-18 months. The only exception is capital base, the correlation size of which was rather stable and was volatile between -0.5 .

Table 8. Lag analysis of Ukrainian real estate market reactions to the changes of MP instruments (monthly data*)

\begin{tabular}{|c|c|c|c|c|c|c|c|}
\hline $\begin{array}{l}\text { Lag size in } \\
\text { months }\end{array}$ & $\begin{array}{c}\text { Discountrateof } \\
\text { NBU }\end{array}$ & $\begin{array}{l}\text { Weighted average rate on all } \\
\text { NBU instruments }\end{array}$ & $\begin{array}{l}\text { Overnight credit } \\
\text { rate }\end{array}$ & $\begin{array}{l}\text { Repotransactions } \\
\text { rate }\end{array}$ & $\begin{array}{l}\text { Credit rate granted } \\
\text { by tender }\end{array}$ & $\begin{array}{l}\text { Capital } \\
\text { base }\end{array}$ & PFTS index \\
\hline 0 & 0.31 & 0.22 & 0.14 & 0.07 & 0.09 & -0.52 & 0.31 \\
\hline 1 & 0.37 & 0.29 & 0.21 & 0.13 & 0.16 & -0.51 & 0.27 \\
\hline 2 & 0.43 & 0.35 & 0.27 & 0.21 & 0.25 & -0.50 & 0.23 \\
\hline 3 & 0.49 & 0.43 & 0.35 & 0.30 & 0.33 & -0.49 & 0.18 \\
\hline 4 & 0.55 & 0.50 & 0.43 & 0.40 & 0.40 & -0.49 & 0.14 \\
\hline 5 & 0.61 & 0.56 & 0.50 & 0.49 & 0.47 & -0.48 & 0.11 \\
\hline 6 & 0.65 & 0.61 & 0.57 & 0.57 & 0.53 & -0.47 & 0.07 \\
\hline 7 & 0.68 & 0.67 & 0.62 & 0.64 & 0.58 & -0.47 & 0.03 \\
\hline 8 & 0.71 & 0.71 & 0.68 & 0.69 & 0.62 & -0.47 & -0.01 \\
\hline 9 & 0.74 & 0.75 & 0.73 & 0.73 & 0.66 & -0.47 & -0.05 \\
\hline 10 & 0.77 & 0.80 & 0.77 & 0.76 & 0.70 & -0.47 & -0.08 \\
\hline 11 & 0.80 & 0.82 & 0.81 & 0.80 & 0.74 & -0.48 & -0.11 \\
\hline 12 & 0.82 & 0.83 & 0.85 & 0.82 & 0.77 & -0.48 & -0.14 \\
\hline 13 & 0.85 & 0.84 & 0.89 & 0.84 & 0.80 & -0.48 & -0.17 \\
\hline 14 & 0.87 & 0.84 & 0.91 & 0.85 & 0.82 & -0.49 & -0.18 \\
\hline 15 & 0.88 & 0.82 & 0.92 & 0.85 & 0.83 & -0.49 & -0.18 \\
\hline 16 & 0.88 & 0.81 & 0.92 & 0.83 & 0.84 & -0.49 & -0.17 \\
\hline 17 & 0.88 & 0.78 & 0.91 & 0.81 & 0.83 & -0.49 & -0.16 \\
\hline 18 & 0.86 & 0.75 & 0.88 & 0.77 & 0.82 & -0.48 & -0.16 \\
\hline 19 & 0.82 & 0.71 & 0.85 & 0.74 & 0.79 & -0.47 & -0.14 \\
\hline 20 & 0.77 & 0.66 & 0.81 & 0.70 & 0.76 & -0.46 & -0.12 \\
\hline 21 & 0.71 & 0.60 & 0.77 & 0.65 & 0.73 & -0.46 & -0.09 \\
\hline 22 & 0.65 & 0.55 & 0.72 & 0.61 & 0.69 & -0.45 & -0.04 \\
\hline 23 & 0.58 & 0.51 & 0.68 & 0.56 & 0.65 & -0.45 & 0.02 \\
\hline 24 & 0.52 & 0.48 & 0.64 & 0.51 & 0.61 & -0.44 & 0.11 \\
\hline
\end{tabular}

Thus, the effect from NBU actions on the secondary real estate market shows itself in 1-1.5 years.

Making conclusions of viability of assets channel implementation into the monetary policy transmission mechanism of Ukraine, it's worth defining the impulses from NBU into the stock market and real estate market are transmitted with great delay. Practically, it is said that there is no direct connection between the actions of NBU and analyzed parts of financial market. The impulses are transmitted to the banking system that perceives them and feels, though the further actions development (that is stock market and real estate market behavior) are not compulsory to be dependent from the primary impulse. Evidently, for these markets, the greater marks are the state of economy in general than the actions of NBU. One of the causes for such state of things is low efficiency of Ukrainian financial market, in whole, and stock market, in particular (Caporale, Gil- Alana, Plastun, Makarenko, 2016).

Nevertheless, with the evidence of developed countries, with time, asset price channel has to play even greater role in transmission mechanism of monetary policy of NBU. 
The proposed approach to the impulses evaluation from NBU to stock market and real estate market of Ukraine (as parts of asset price channel) may be used by the specialists of NBU for quantitative and qualitative evaluation of asset price channel, as well as while constructing mathematical models that describe the behavior of asset price channel in transmission mechanism of monetary policy of Ukraine.

\section{The ways of asset price channel in corporation in transmission mechanism of monetary policy of Ukraine}

Not taking into account the absence of direct connection between the actions of NBU and asset prices, it is evident that asset price channel has to be the integrated part of transmission mechanism of monetary policy of Ukraine. The experience of developed countries witnesses about this, as well as about asset prices is the unique source of information for the Central Bank concerning the country's economy state. The uniqueness lies primarily in the financial markets incorporation speed of new information concerning the state of economy in asset prices. Besides, the uniqueness of asset price channel also lies in information quality, as prices for financial assets are formed as a result of interaction of great number of financial professionals (analytics, traders, investors, speculators and so on).

Thus, while developing monetary policy, the Central Bank has not only to take into account the meanings of key macroeconomic parameters, but also do the asset prices monitoring on financial markets with the aim of quick correcting of own actions depending on the current state of the country's economic state.

Financial markets prices monitoring by the Central Bank and its indirect regulation through the monetary policy instruments is very important. Thus, the collapse of price bubbles leads to great economic shocks and economic crises appearance and temporary disbalances in economy. Rather often the mild monetary policy stimulates the bubbles appearance and, on the contrary, its reorientation to tighter one leads to the collapse of price bubbles. Thus, in the development and realization of monetary policy, the Central Bank has to take into account the price behavior nuances to the assets with the aim of not letting the appearance and accidental collapse of price bubbles. In turn, it is possible only by the asset price channel implementation to the monetary policy transmission mechanism.

It is worth mentioning the most part of scientists and representatives of Central Banks who admit that the decision on discount rate implementation has to be the answer to the current and perspective inflation or abruptions in manufacturing, and not on the asset price dynamics. That is, in equation that determines current rates level of Central Bank, the introduction of assets price variable is inappropriate. This change has to be present as additional variable in equations of the second, third and other levels of transmission mechanism (see for details Bernanke and Gertler, 2001). It is explained by the great price volatility level on the financial assets. The systematic reaction of Central Bank to the financial assets price volatility may lead to chaos and definite disbalance in monetary policy and economic agents' actions.

Classifying the researches of different scientists on viability of asset price channel incorporation to the monetary transmission mechanism and the mechanism of taking decisions by Central Bank, we may define arguments for the benefit of asset price channel:

1. Central Bank actions correction depending on asset price dynamics lessens the possibility of price bubbles appearance that lessens the possibility of crisis events as a result of price bubbles collapse;

2. While measuring the basis inflation taking into account the real estate price is appropriate, at the same time the prices for different financial assets may be ignored;

3. Asset prices contain the information about future inflation, which maybe included into the inflation forecasts that are conducted in terms of monetary policy realization. Thus, while forecasting financial assets prices it is possible to forecast the inflation.

In terms of asset price channel implementation into the transmission mechanism of monetary policy of Ukraine, the asset prices may influence investment expenditures, consumption, manufacturing and inflation processes in the country.

For instance, expansionary monetary policy leads to growing of crediting volumes, which leads to the appearance of free money among economic agents that they try to put up in getting any assets, at the same time, in buying entities' shares, which leads to the rise of their market prices. Thus, Tobin's q variable begins to rise (Tobin's q variable is defined as market value of the firm, divided into renovated capital value), and, then, investment expenses and GDP rise.

Stock market and real estate asset price reduction (financial wealth reduction and collateral value effects), as well as market value of companies in relation to renovated capital expenses (Tobin's q effect) influence the worsening of creditworthiness of borrowers, and, consequently, negatively impacted the credit, consuming, investment and manufacturing activity of market subjects. It 
enforces the economic cycle amplitude (financial accelerator effect), exacerbates crisis processes of economic fall, and becomes one of the demand reduction, proposition and inflation factors in the country.

Asset price incorporation into the transmission mechanism also lets to evaluate technology shocks in economy, connected with great scientific discoveries, and which directly impact products manufacturing, employment and level of life. Thus, asset price rise makes firms' balance accounting better and stimulates future investments. Investment volume enlarging, in it turn, may lead to different asset prices rising and money flow growing including reverse effect from incurred expenses. Financial accelerator mechanism is an important element in asset price transmission channel.

In terms of definite economic relations in the transmission mechanism, in which asset prices take part, the following examples may be presented.

The change of discount rate by Central Bank creates the interest rate impulse that spreads in economic system (Fig. 2).

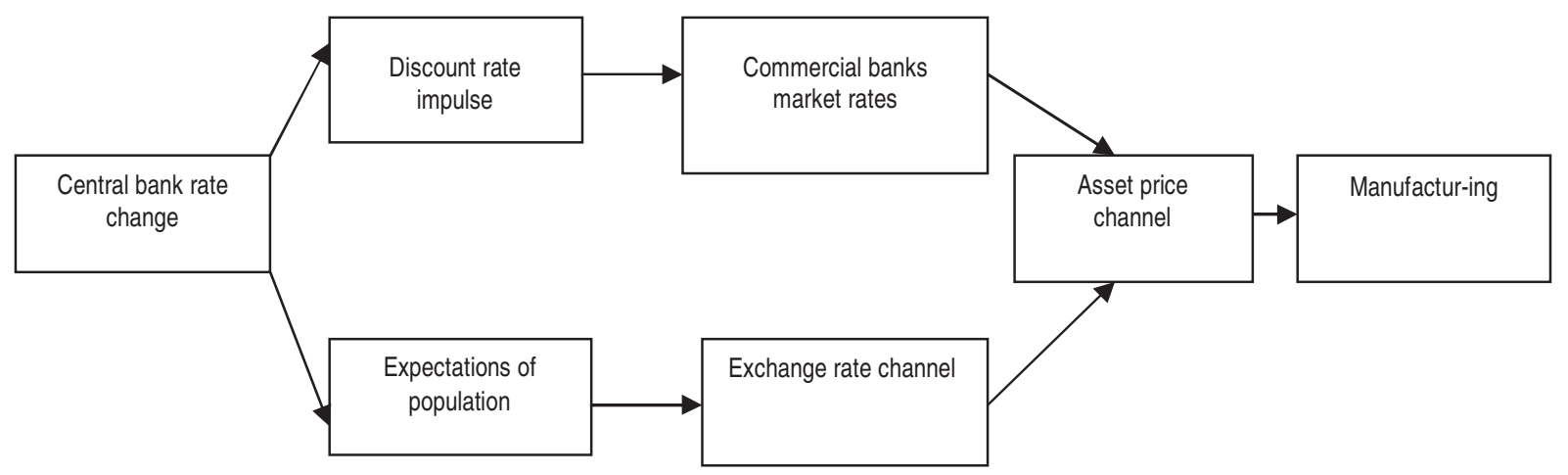

Fig. 2. The place of asset price channel in the transmission mechanism

The approximate following scheme of asset price channel incorporation in the transmission mechanism (Fig. 3).

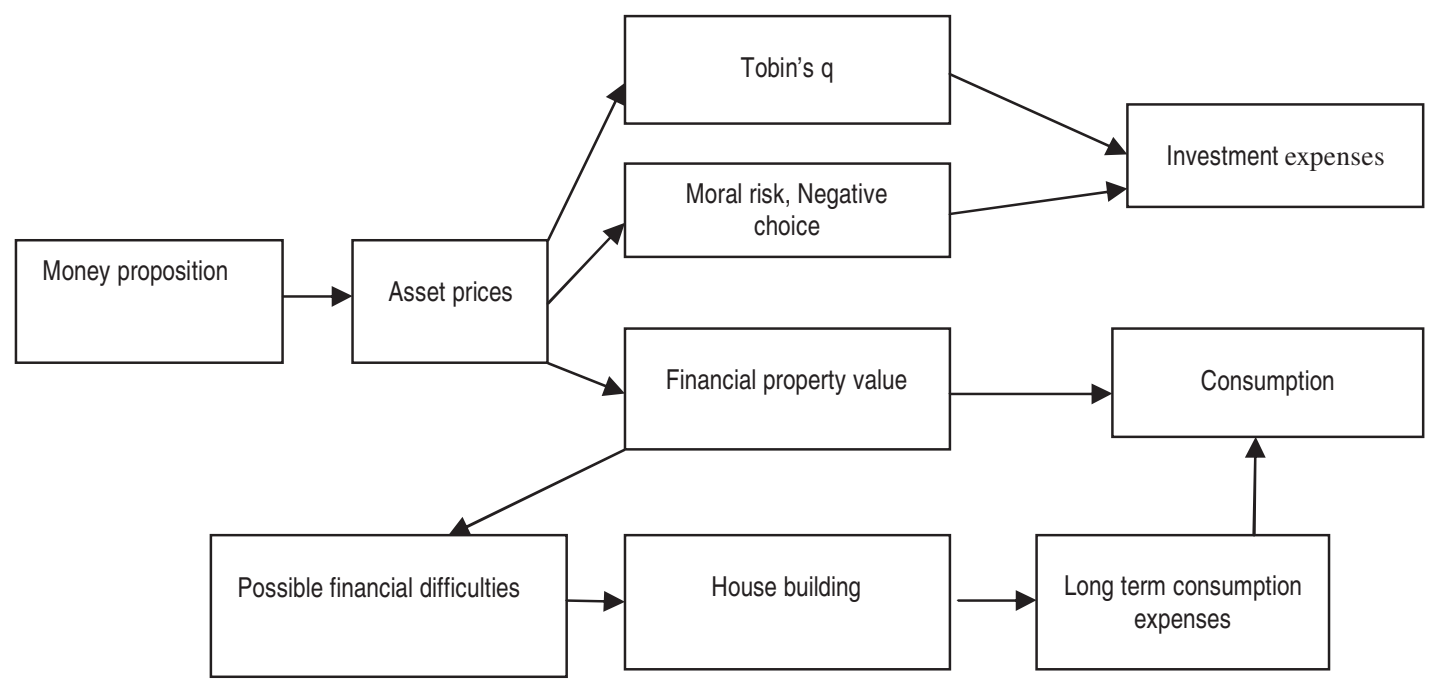

Fig. 3. Asset price channel incorporation in the transmission mechanism of monetary policy of Ukraine

Also, asset prices may perform as one of the variables in equation, which determines inflation level. As asset, prices on stock markets, future prices for goods and services perform (see for details Cecchetti et al., 2000). Asset prices may perform as indicators for future inflation level parameters determining.In the West, a great number of researches on relation existence between retail prices and asset price volatility were held.Most of them prove the existence of statistically significant relation between asset prices, real estate and retail prices and future inflation.
Except the aforementioned, we may outline additional effects that appear during the transmission mechanism process appearance, connected with asset prices. Thus, the Central Bank of England includes real estate prices into the transmission mechanism model that perform as quantitative evaluation of households' net financial wealth. Besides, asset prices on world stock markets, returns from long term government securities of Great Britain as well as the USA influence households' net financial wealth parameter. 


\section{Conclusions}

Monitoring and quantitative asset price evaluation is an important element of modern transmission mechanism.

The speed of stock market prices reactions to the changing economic surrounding makes the asset price channel a unique source of information for the central bank during its monetary policy development and correction. And although conducted analysis showed in Ukraine for today the asset price channel practically did not work, its perspectives are undoubted that provokes the recommendations development need and importance on asset price channel in transmission mechanism of monetary policy of Ukraine.

\section{References}

1. Batini, N. and E. Nelson. (2000).Optimal Horizons for Inflation Targeting, Bank of England Working Papers.

2. Bernanke Ben S., Mishkin, Frederic S. (1997). InflationTargeting: A New Frame work for Monetary Policy? The Journal of Economic Perspectives, Vol. 11, No. 2, pp. 97-116.

3. Bernanke, Ben S. and Mark Gertler. (2001). Should Central Banks Respond to Movements in Asset Prices? The American Economic Review, Vol. 91, No. 2, Papersand Proceedings of the Hundred Thirteenth Annual Meeting of the American Economic Association, May 2001, pp. 253-257.

4. Caporale, Guglielmo Maria, Gil-Alana, Luis, Plastun, Alexand Makarenko, Inna. (2016). Long memory in the Ukrainian stock market and financial crises, Journal of Economics and Finance, April 2016, Volume 40, Issue 2, pp. 235-257.

5. Cecchetti, Stephen, Genberg, Hans, Lipsky, Johnand Wadhwani, Sushi. (2000). Asset prices and central bank policy. London: International Center for Monetary and Banking Studies.

6. Ivanchenko, I. (2010). Influence of monetary impulses on the stock assets prices, Journal of Banking, №3, pp.50-54.

7. Ivanov, M.andI. Lavrinovich. (2008).MonetaryTransmission mechanism and behaviour of asset prices: the case of Croatia, Review of Business Research, Volume 8, Number 2,pp. 1-18.

8. Kent, C. and P. Lowe. (1997). Asset-Price Bubbles and Monetary Policy, Research Discussion Paper 9709, Economic Research Department, Reserve Bank of Australia.

9. Kozmenko, S., Taras Savchenko, and Yanina Piontkovska. (2014). Development and application of the monetary rule for the base interest rate of the National Bank of Ukraine, Banks and Bank Systems, Volume 9, Issue 3, pp. 50-58.

10. Kozmenko, S. And T. Savchenko. (2011). Countercyclical monetary policy in major economies of the Common wealth of Independent States, Investment Management and Financial Innovations, № 4, pp. 8-19.

11. Kozmenko, S. And T. Savchenko. (2013). Development of an explicit rule of monetary policy for the economy of Ukraine, Investment Management and Financial Innovations International Research Journal. № 1, pp. 8-19.

12. Kozmenko, Serhiy and Oleksiy Plastun. (2012). The necessity of stockmarkets in formation in corporation into the methodology of credit rating agencies, Investment Managementand Financial Innovations International Research Journal. Volume 9, pp. 50-58.

13. Mishkin, F.S. (1995). Symposium on the Monetary Transmission Mechanism, Journal of Economic Perspectives, №9 (4), pp. 3-10.

14. Poole, W. (1970). Optimal Choice of Monetary Policy Instruments in a Simple Stochastic MacroModel, Quarterly Journal of Economics, 88, pp. 197-216.

15. Roger, Sandra and Gabriel Sterne. (1999). The Devil in the Detail Monetary Policy Frameworks: Issues and Measurements of Monetary Framework Characteristics. In Fry, Maxwell and others, Monetary Policy Frameworks in a Global Context, CCBS, Bank of England.

16. The transmission mechanism of monetary policy.The Monetary Policy Committee Bank of England. Available at: http://www.bankofengland.co.uk/publications/Documents/other/monetary/montrans.pdf. 